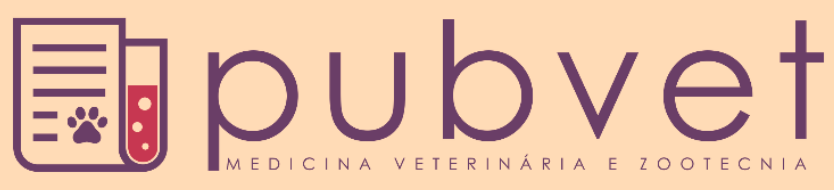

https://doi.org/10.31533/pubvet.v14n11a689.1-5

\title{
Análise de microrganismos deteriorantes em derivados lácteos fermentados durante o prazo comercial
}

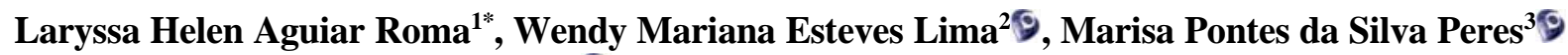 \\ Stefania Márcia de Oliveira Souza ${ }^{4} 9$ \\ ${ }^{I}$ Médica veterinária. Pós-graduanda em Gestão da Qualidade, Higiene e Tecnologia de POA pelo Ifope Educacional. \\ ${ }^{2}$ Bióloga, Técnica no laboratório de microbiologia do Centro Universitário do Planalto Central Apparecido dos Santos - UNICEPLAC. \\ ${ }^{3}$ Médica veterinária. Pós-graduanda em Gestão da Qualidade, Higiene e Tecnologia de POA pelo Ifope Educacional. \\ ${ }^{4}$ Dra. Médica veterinária e Professora do Centro Universitário do Planalto Central Apparecido dos Santos - UNICEPLAC. \\ *Autor para correspondência, E-mail: laryssahelen@hotmail.com
}

\begin{abstract}
Resumo. O leite é um alimento rico em nutrientes e está presente em refeições diárias, tanto in natura como nos derivados lácteos. Os derivados estão associados à manutenção da saúde, e nessa categoria destacam-se os leites fermentados. Tendo em vista a segurança do alimento e visando a eliminação das doenças transmitidas por eles, a qualidade microbiológica é um importante parâmetro a ser avaliado nessa condição, já que seus resultados apontarão uma provável fonte de contaminação a qual esse alimento foi submetido. Esse trabalho teve como objetivo a análise da microbiota deteriorante de produtos lácteos: iogurte, leite fermentado e bebida láctea, com finalidade de apontar possíveis contaminações durante os processos de produção e beneficiamento, evidenciando as populações de coliformes, psicotróficas proteolítica e lipolítica, ao longo do prazo de validade. No que diz respeito às atividades lipolítica e proteolítica, respectivamente, nenhuma cepa apresentou ação sobre a gordura suína ou na proteína do leite.
\end{abstract}

Palavras chave: Bactérias ácido-láticas, Consumidor, Fermentação, Shelf-life

\section{Analysis of microorganisms deteriorated in dairy products fermented during the commercial period}

\begin{abstract}
Milk is a nutrient-rich food and is present in daily meals, both fresh and dairy products. Derivatives are associated with health maintenance, and in this category stand out fermented milk. In view of the safety of the food and aiming at the elimination of diseases transmitted by them, microbiological quality is an important parameter to be evaluated in this condition, since its results will indicate a probable source of contamination to which this food was submitted. objective the analysis of the deteriorating microbiota of dairy products: yogurt, fermented milk, and milk drink, aiming to point out possible contamination during the production and processing processes, highlighting the populations of coliforms, proteolytic and lipolytic, throughout the shelf life. Regarding lipolytic and proteolytic activities, respectively, no strain had action on swine fat or milk protein.
\end{abstract}

Keywords: Lactic acid bactéria, Consumer, Fermentation, Shelf-life

\section{Análisis de microorganismos deteriorados en productos lácteos fermentados durante el período comercial}

Resumen. La leche es un alimento rico en nutrientes y está presente en las comidas diarias, tanto frescas como en productos lácteos. Los derivados están asociados con el 
mantenimiento de la salud, y en esta categoría, se destacan las leches fermentadas. En vista de la inocuidad de los alimentos y con el objetivo de eliminar las enfermedades transmitidas por ellos, la calidad microbiológica es un parámetro importante para ser evaluado en esta condición, ya que sus resultados señalarán una fuente probable de contaminación a la que se sometió este alimento. Este trabajo tuvo como objetivo analizar el deterioro de la microbiota de los productos lácteos: yogur, leche fermentada y bebidas lácteas, con el objetivo de señalar la posible contaminación durante los procesos de producción y procesamiento, mostrando las poblaciones de coliformes, psicrotróficos proteolíticos y lipolíticos, a lo largo del período de validez. Con respecto a las actividades lipolíticas y proteolíticas, respectivamente, ninguna cepa tuvo ningún efecto sobre la grasa porcina o la proteína de la leche.

Palabras clave: Bacterias de ácido láctico, consumidor, fermentación, vida útil

\section{Introdução}

Segundo pesquisas realizadas em âmbito mundial, a desconformidade com os padrões estabelecidos em lei caracteriza potencial risco à saúde do consumidor (Rodas et al., 2001). A preocupação das indústrias manipuladoras de produtos de origem animal é ainda maior quando relacionada às doenças transmitidas por alimentos. Devido a essa responsabilidade do setor alimentício com a saúde pública, a legislação exige o desenvolvimento de programas de autocontrole que visam maior higienização em todos os processos produtivos, desde a fabricação, expedição até a distribuição (Souza et al., 2016).

Tendo em vista a segurança do alimento e visando a eliminação das doenças transmitidas por eles, a qualidade microbiológica é um importante parâmetro a ser avaliado nessa condição, já que seus resultados apontarão uma provável fonte de contaminação ao qual esse alimento foi submetido (Menezes et al., 2015). O conhecimento sobre as características das condições microbiológicas as quais o produto apresenta, conduzirá o produtor quanto às prováveis falhas higiênicas no processo de manipulação e envase, dessa forma, poderá trabalhar aspectos dentro da indústria que estão relacionados às boas práticas de fabricação (Souza et al., 2016).

Dessa forma, esse trabalho teve como objetivo a análise da microbiota deteriorante de produtos lácteos: iogurte, leite fermentado e bebida láctea, com finalidade de apontar possíveis contaminações durante os processos de produção e beneficiamento, evidenciando as populações coliformes, psicotróficas proteolítica e lipolítica, ao longo do prazo de validade.

\section{Material e métodos}

Foram analisados derivados lácteos comercializados: iogurte, leite fermentado e bebida láctea fermentada, todos com preparos de fruta morango. Após aquisição em estabelecimento comercial, os produtos mantidos em suas embalagens originais transportados em condição de refrigeração (caixa isotérmica com gelo), foram conduzidos para análises no laboratório de Microbiologia do Centro Universitário do Planalto Central Apparecido dos Santos. Todos os produtos foram adquiridos na região do Gama - DF. Os produtos com a mesma composição eram provenientes do mesmo lote, validade e fabricação, e com certificação de registro pelo sistema de inspeção.

Foram adicionados $25 \mathrm{~mL}$ de cada produto em recipientes de vidro previamente esterilizados, e devidamente identificados, para posteriores análises. As amostras foram identificadas como Iogurte (I), leite fermentado (LF), e bebida láctea (BL). Os produtos foram analisados a cada cinco dias, sendo o dia da aquisição o dia 0 (D0) e os demais inóculos D5, D10, D15 e D20.

Todas as amostras foram submetidas às análises de microrganismos psicotróficos proteolíticos, coliformes totais, coliformes termotolerantes e lipolíticos. Alíquota de $25 \mathrm{~mL}$ das amostras de cada produto (I, LF e BL) foram pipetadas em $225 \mathrm{~mL}$ de solução salina a $0,85 \%$ (diluição $10^{-1}$ ), respectivamente, homogeneizadas, e distribuídas em diluições seriadas $\left(10^{-2}\right.$ a $\left.10^{-5}\right)$ efetuadas em $9 \mathrm{~mL}$ de solução salina a $0,85 \%$. A diluição escolhida para todas as análises foi a $10^{-3}$.

A presença de coliformes totais é feita por meio da inoculação das colônias em caldo verde brilhante bile $2 \%$ lactose e posterior incubação a $35^{\circ} \mathrm{C} \pm 1{ }^{\circ} \mathrm{C}$. A presença de gás nos tubos de Durham evidencia 
a fermentação da lactose presente no meio. A confirmação da presença de coliformes termotolerantes é feita por meio da inoculação das colônias suspeitas em caldo EC e posterior incubação em temperatura seletiva de $45^{\circ} \mathrm{C} \pm 0,2{ }^{\circ} \mathrm{C}$ (Brasil, 2018) .

Para verificar a atividade e enumeração de lipolíticos, foi preparado o meio seletivo Ágar Tributirina $\left(\right.$ SIGMA-ALDRICH $\left.^{\circledR}\right)$. Para suplementar, como meio alternativo foi adicionado $1,0 \%$ de banha de porco baseado na metodologia utilizada por Carpiné et al. (2010) com algumas alterações. O meio foi emulsionado por agitador magnético por cinco minutos, o $\mathrm{pH}$ do foi ajustado a 6,5 e autoclavado a 121 ${ }^{\circ} \mathrm{C}$ por quinze minutos. Foram inoculados em duplicata $0,1 \mathrm{~mL}$ na superfície das placas contendo o meio de cultivo, espalhado com auxílio da alça de drigalski. Após esse processo, as placas foram incubadas em diferentes temperaturas, a $37^{\circ} \mathrm{C} \mathrm{e} 7^{\circ} \mathrm{C}$, respectivamente por 7 dias.

$\mathrm{Na}$ avaliação microbiológica dos microrganismos psicotróficos proteolíticos, foi instituído o meio de Plate Agar Count (PCA) (KASVI ${ }^{\circledR}$ ) suplementado com $10 \%$ de leite em pó desnatado preparado conforme a metodologia utilizada por Ferreira et al. (2019) com alterações. Alíquotas de 0,1 mL foram pipetadas nas placas de petri contendo o meio preparado, ágar leite. $\mathrm{O}$ espalhamento foi realizado com alça de drigalski e após esse procedimento as placas foram invertidas e incubadas a $7{ }^{\circ} \mathrm{C}$ por 7 dias.

\section{Resultados e discussão}

A Portaria no 368/97, do Ministério da Agricultura, Pecuária e Abastecimento (MAPA) estabelece os requisitos essenciais de higiene e de boas práticas de elaboração para alimentos elaborados/industrializados para o consumo humano. As Boas Práticas de Fabricação (BPF) são definidas como o conjunto de diretrizes, normas e procedimentos, exigidos na elaboração de produtos alimentícios industrializados para o consumo humano, cujo objetivo principal é assegurar que os produtos sejam sempre fabricados com a qualidade exigida, com ênfase na pureza e segurança (Brasil, 1977).

$\mathrm{Na}$ análise de coliformes totais e termotolerantes, não houve turvação nem presença de gás nos tubos de Durham, o que evidenciaria a fermentação da lactose presente no meio. A ausência de coliformes no produto final, pode ser indicativo de boas condições higiênico-sanitárias durante o processo de elaboração das bebidas. Desta forma, pode-se afirmar que os produtos estavam dentro dos padrões de qualidade higiênicas sanitárias.

Para detectar atividade lipolítica, os resultados são verificados pela formação de halos ao redor das colônias. Todas as placas apresentaram resultado negativo para a atividade lipolítica no ágar Tributirina. De acordo com Papon \& Talon (1988) e Reuter (1975), as espécies de Lactobacillus presente nos derivados apresentam fraca atividade lipolítica. Esse estudo destaca que as informações na literatura são escassas quanto a verificação de atividade lipolítica de bactérias láticas.

As bactérias psicotróficas são as principais responsáveis pela deterioração do leite cru refrigerado e de seus derivados, e se caracterizam por terem a habilidade de se desenvolverem em baixas temperaturas, menor ou igual de $7{ }^{\circ} \mathrm{C}$, embora a temperatura ideal para seu crescimento, seja entre $20 \mathrm{e}$ $30{ }^{\circ} \mathrm{C}$. Estas bactérias desencadeiam a atividade deteriorante ao produzirem proteases, lipases e fosfolipases, as quais hidrolisam a proteína e a gordura do leite. Apesar de a maior parte das bactérias psicotróficas não resistirem ao processo da pasteurização, muitas de suas enzimas hidrolíticas são termoresistentes, continuando sua atividade mesmo ao tratamento UHT. A existência dessas enzimas termotolerantes, no leite cru, pode trazer prejuízo à qualidade do leite UHT (Arcuri et al., 2008).

Zeni et al. (2013) citaram que não há um padrão descrito na legislação para as contagens de microrganismos psicotróficos. Portanto, vários estudos demonstram contagens bacterianas com grande potencial que interferem na qualidade dos produtos lácteos.

Devido ao crescente aumento no seu consumo pela população nacional e internacional, os produtos lácteos são muito importantes para o mercado alimentício. Isso faz com que cresça a preocupação em desenvolver estudos para a melhoria de sua qualidade (Soares et al., 2011). O metabolismo dos microrganismos psicotróficos em temperaturas menores a $10^{\circ} \mathrm{C}$ torna-se preeminente lipo-proteolítico manifestando-se pela produção de enzimas intra e extracelulares. A produção das enzimas hidrolíticas se refere a fase máxima de crescimento exponencial ou estacionária (Champagne et al., 1994). 
O grupo de microrganismos psicotróficos inclui bactérias Gram-positivas e negativas. Em países de clima temperado, de acordo com alguns estudos, os principais gêneros isolados são: Bacillus, Clostridium, Microbacterium, Streptococcus, Corynebacterium, Arthrobacter (Gram-positivas), Pseudomonas, Flavobacterium e Alcaligenes (Gram-negativas) e bactérias patogênicas como Listeria monocytogenes, Yersinia enterocolitica e algumas estirpes de Bacillus cereus isoladas de leite também são consideradas psicotróficas (Arcuri et al., 2008).

Dentre os principais problemas decorrentes dos altos números de bactérias psicotróficas nos produtos lácteos, destaca-se as modificações na consistência e textura, sabores e odores desagradáveis (que pode ser durante a estocagem e maturação) e rancificação, devido a produção de lipases e proteases termo resistentes, que podem continuar atuando mesmo após a pasteurização rápida ou processamento a ultra alta temperatura (Rodríguez et al., 2005).

Em relação à psicotróficos proteolíticos, nenhum microrganismo foi encontrado durante o período de análises dos produtos. A detecção de bactérias psicotróficas proteolíticas baseia-se na visualização da formação de halos de proteólise nas placas de Agar (Nörnberg et al., 2009).

Pereira et al. (2008) explicam que o não aparecimento de bactérias psicotróficas proteolíticas, não significa um derivado íntegro, já que o tratamento térmico do leite inativa essas bactérias, portanto suas enzimas continuam ativas no produto. Isto propõe que apesar de não ter sido possível a detecção de microrganismos no estudo, suas enzimas podem agir sobre os componentes do derivado lácteo causando alterações de odor e sabor, porém essas características não foram avaliadas na presente pesquisa.

De acordo com o estudo de Santana et al. (2001), ao analisarem diferentes marcas de leites fermentados, algumas delas não apresentaram presença de psicotróficos proteolíticos, $o$ autor associa que esse resultado pode ter ocorrido por inicialmente haver aumento no crescimento das bactérias lácticas presentes no iogurte que produzem compostos de ação antimicrobiana, inibindo o crescimento de outros microrganismos.

\section{Conclusão}

Os produtos analisados apresentaram-se de acordo com a qualidade higiênica sanitária prevista na legislação, uma vez que não foram detectados coliformes e deterioração durante as análises dentro do prazo de validade comercial. No que diz respeito às atividades lipolítica e proteolítica, respectivamente, nenhuma cepa apresentou ação sobre a gordura suína ou na proteína do leite. Os resultados obtidos no presente trabalho demonstram que o processo higiênico de fabricação dos produtos analisados e o armazenamento em temperaturas adequadas permitem a conservação do produto e evitam a multiplicação de microrganismos com capacidade de deterioração de seus componentes.

\section{Referências}

Arcuri, E. F., Silva, P. D. L., Brito, M. A. V. P., Brito, J. R. F., Lange, C. C., \& Magalhães, M. M. A. (2008). Contagem, isolamento e caracterização de bactérias psicrotróficas contaminantes de leite cru refrigerado. Ciência Rural, 38(8), 2250-2255. https://doi.org/10.1590/S0103-84782008000800025

Brasil. (1977). Portaria $\mathrm{n}^{\circ}$ 368, de 04 de set. de 1997. Regulamento Técnico Sobre as Condições Higiênicos-Sanitárias e de Boas Práticas de Elaboração Para Estabelecimentos Elaboradores/ Industrializadores de Alimentos. Brasília, DF, Set.

Brasil. (2018). Instrução Normativa $\mathrm{n}^{\circ}$ 30, de 26 de jun. de 2018. Manual de Métodos Oficiais Para Análise de Alimentos de Origem Animal. Brasília, DF, Jun 2018.

Carpiné, D., Dagostin, L. A., Santa, H. S. D., Alvarez, D. C., Terra, N. N. \& Santa, O. R. D. (2010). Atividade proteolítica e lipolítica de bactérias láticas isoladas de salames artesanais. Ambiência, 6(1).

Champagne, C. P., Laing, R. R., Roy, D., Mafu, A. A., Griffiths, M. W., \& White, C. (1994). Psychrotrophs in dairy products: Their effects and their control. Critical Reviews in Food Science and Nutrition, 34(1), 1-30. https://doi.org/10.1080/10408399409527648

Ferreira, M. L., Palhares, G. L., Silva, A. A., \& Souza, S. M. O. (2019). Análise de psicrotróficos e psicrotróficos proteolíticos em iogurte integral. Pubvet, 13(5), 1-8. https://doi.org/10.31533/pubvet.v13n5a330.1-8

Menezes, I. R., Almeida, A. C., Morão, R. P., Reis, S. V., Santos, C. A. \& Lopes, I. L. N. (2015). 
Qualidade microbiológica do leite cru produzido no Norte de Minas Gerais. Revista Brasileira de Ciência Veterinária, 22(1), 58-63. https://doi.org/10.4322/rbcv.2015.321

Nörnberg, M. F. B. L., Tondo, E. C., \& Brandelli, A. (2009). Bactérias psicrotróficas e atividade proteolítica no leite cru refrigerado. Acta Scientiae Veterinariae, 37(2), 157-163.

Papon, M., \& Talon, R. (1988). Factors affecting growth and lipase production by meat lactobacilli strains and Brochothrix thermosphacta. Journal of Applied Bacteriology, 64(2), 107-115. https://doi.org/10.1111/j.1365-2672.1988.tb02729.x

Pereira, C. I., Gomes, E. O., Gomes, A. M. P., \& Malcata, F. X. (2008). Proteolysis in model Portuguese cheeses: Effects of rennet and starter culture. Food Chemistry, 108(3), 862-868. https://doi.org/10.1016/j.foodchem.2007.11.050

Reuter, G. (1975). Classification problems, ecology and some biochemical activities of lactobacilli of meat products. Lactic Acid Bacteria in Beverages and Food: Proceedings of a Symposium.

Rodas, M. A. B., Rodrigues, R. M. M. S., Sakuma, H., Tavares, L. Z., Sgarbi, C. R., \& Lopes, W. C. C. (2001). Caracterização físico-química, histológica e viabilidade de bactérias lácticas em iogurtes com frutas. Ciência e Tecnologia de Alimentos, 21(3). https://doi.org/10.1590/S0101-20612001000300009

Rodríguez, M. I. C., Alvarez, L. F., Sanz, M. L. G., Minguillón, G., Pirales, L. L. H., \& Cotocero, M. D. S. (2005). Tecnologia de Alimentos-Alimentos de origem Animal. São Paulo, 2.

Santana, E. H. W., Beloti, V., Barros, M. de A. F., Moraes, L. B., Gusmão, V. V., \& Pereira, M. S. (2001). Contaminação do leite em diferentes pontos do processo de produção: I. Microrganismos aeróbios mesófilos e psicrotróficos. Semina: Ciências Agrárias, 22(2), 145-154.

Soares, D. S., Fai, A. E. C., Oliveira, A. M., Pires, E. M. F., \& Stamford, T. L. M. (2011). The use of cheese whey for probiotic yogurt production. Arquivo Brasileiro de Medicina Veterinária e Zootecnia.

Souza, A. R., Filho, W. F. L., Silva, G. A., \& Prado, R. S. (2016). Análise microbiológica de leite cru refrigerado e industrializado proveniente de propriedades dos municípios de Carmo do Rio Verde, Itapaci, Ipiranga de Goiás, Nova América, Rubiataba e São Patrício-Goiás. Revista Eletrônica Da Faculdade de Ceres, 5(1). https://doi.org/10.36607/refacer.v5i1.3359

Zeni, M. P., Maran, M. H. S., Silva, G. P. R., Carli, E. M., \& Palezi, S. C. (2013). Influência dos microrganismos psicrotróficos sobre a qualidade do leite refrigerado para produção de UHT. Unoesc \& Ciência-ACET, 4(1), 61-70.

Histórico do artigo:

Recebido: 30 de junho, 2020.

Aprovado: 3 de agosto, 2020 .

Disponível online: 23 de outubro, 2020.
Licenciamento: Este artigo é publicado na modalidade Acesso Aberto sob a licença Creative Commons Atribuição 4.0 (CC-BY 4.0), a qual permite uso irrestrito, distribuição, reprodução em qualquer meio, desde que o autor e a fonte sejam devidamente creditados. 